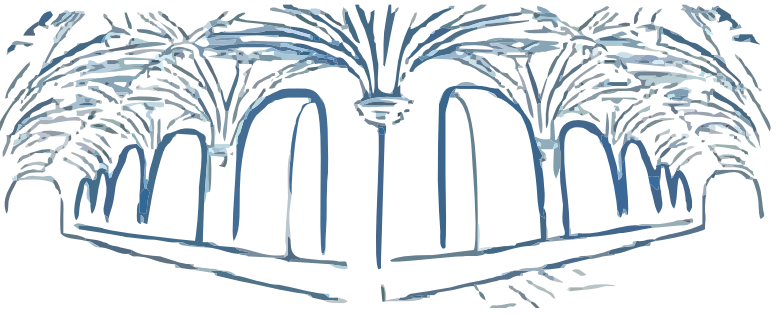

Marques Santos, P., Guedes, A., Oliveira, I., \& Antunes, S. (2021). Gestão de eventos estudo da metodologia de ensino e avaliação da UC no ensino superior.

Revista Practicum, 6(2), 70-84.

https://doi.org/10.24310/RevPracticumrep.v6i2.10578
R E V I S T A PRACTICUM

Número 6(2), Julio-Diciembre, 2021 ISSN: 2530-4550

Fecha de recepción: 26/10/2020 Fecha de aceptación 23/11/2020

\title{
Gestão dle eventos - estudo da metodologia de ensino e avaliação da UC no ensino superior
}

\section{Event management - teaching and assessment methodology of an Unit in higher education}

\author{
Paula Marques Santos \\ Instituto Politécnico de Viseu (Portugal) \\ psantos@estgl.ipv.pt \\ Anabela Guedes \\ Instituto Politécnico de Viseu (Portugal) \\ aguedes@estgl.ipv.pt \\ Isabel Oliveira \\ Instituto Politécnico de Viseu (Portugal) \\ ioliveira@estgl.ipv.pt \\ Sandra Antunes \\ Instituto Politécnico de Viseu (Portugal) \\ santunes@estgl.jpv.pt
}

\section{Resumo}

Este artigo pretende apresentar um estudo sobre a metodologia de ensino e avaliação da unidade curricular de gestão de eventos, garantindo a aquisição de conhecimento e competências adequadas às solicitações e necessidades do mercado de trabalho. Como principais objetivos, temos: entender a importância do ensino de gestão de eventos; explicar a metodologia de ensino e de avaliação colaborativa na Unidade Curricular; identificar as principais vantagens da 
metodologia utilizada para aquisição de conhecimentos científicos e técnicos. Metodologicamente, na dimensão empírica do nosso trabalho, de natureza essencialmente descritiva, tentamos explicar todas as ferramentas de ensino e avaliação em uso e como elas ajudam os alunos na aquisição de conhecimentos. 0 presente estudo analisa como o ensino ativo e colaborativo pode ser usado em licenciaturas, com base em métodos práticos para ajudar os alunos a adquirir as competências necessárias, esquematizando-se as principais competências e evidenciando a importância da qualificação específica em gestão de eventos.

\section{Abstract}

This article intends to present a study on the teaching and evaluation methodology of the event management course unit, ensuring the acquisition of knowledge and skills appropriate to the demands and needs of the labour market. The main objectives are: to understand the importance of teaching event management; explain the teaching and collaborative assessment methodology in the Course; identify the main advantages of the methodology used to acquire scientific and technical knowledge. Methodologically, in the empirical dimension of our work, which is essentially descriptive in nature, we try to explain all the teaching and assessment tools in use and how they help students in acquiring knowledge. The present study examines how active and collaborative teaching can be used in undergraduate courses, based on practical methods to help students acquire the necessary skills, outlining the main competencies and highlighting the importance of specific training in event management.

\section{Palavras - chave}

Gestão de eventos, avaliação de aprendizagem, metodologia de ensino, competências críticas, soft skills.

\section{Keywords}

Event management, learning assessment, teaching methodology, hard, soft skills.

\section{O Ensino superior e a aquisição de conhecimento através de metodologias ativas}

\subsection{Ensino e soft slsills}

A aquisição de conhecimento (científico e técnico) e a capacidade de transmitir aos alunos a importância do domínio de quadros de conhecimento abstra- 
tos, capazes de serem adaptados a situações concretas do mundo do trabalho, são dos maiores desafios da qualificação superior, especialmente nos cursos de 10 ciclo (licenciaturas). De facto, o ensino superior tem por missão capacitar os futuros profissionais, através de uma preparação adequada às exigências profissionais, tornando-os em recursos valiosos e imprescindíveis para as organizações atuais, não só pelo conhecimento técnico especializado adquirido - hard skills (nas áreas respetivas da sua formação), mas também pelo domínio de competências (comunicacionais, interpessoais e organizacionais, além das emocionais, sociais e cognitivas) que facilitem a sua adaptabilidade a qualquer ambiente profissional - soft skills.

A mudança do foco, centrado anteriormente num ensino puramente académico de transmissão unidirecional de informação (professor - aluno), evidencia que as soft skills e a própria competência de aprender são uma parte essencial para a formação integral do aluno, promovendo a própria inteligência emocional, como um dos fatores chave para o seu êxito profissional. De acordo com o Relatório da UNESCO (1996), aprender deve basear-se em competências que capacitem o indivíduo para inúmeras situações reais, algumas delas imprevisíveis, além de facilitarem o trabalho em equipa (competência esta muitas vezes negligenciada nos métodos tradicionais de ensino). Para isso, a matriz curricular das Instituições de Ensino Superior (IES) deve passar por um processo de desconstrução, onde o aluno se torne protagonista nos processos de ensino e de aprendizagem, sendo corresponsável pelo seu percurso académico.

As soft skills são, por isso, essenciais nestes processos de ensino e de aprendizagem, constituindo-se como ferramentas que ajudarão os alunos a gerir conflitos e a criar relacionamentos inclusivos, os quais melhoram o desempenho do grupo (turma, equipa de trabalho, etc.), promovem a produção de ideias, a negociação de soluções e a reformulação de processos de trabalho (Englan et al., 2020). Neste sentido, a preparação integral do aluno através destas "novas" competências facilitará o desenvolvimento da sua inteligência emocional e potenciará as suas oportunidades de sucesso profissional.

O conceito de inteligência emocional é relativamente recente e, como as questões emocionais não eram normalmente abordadas na educação (em casa ou na escola), os indivíduos tinham de aprender a lidar com as suas emoções da maneira que podiam. Assim, na ausência de uma educação emocional explícita, a sociedade produziu analfabetos emocionais (Fernández-Berrocal et al., 2001). Todavia, nem sempre a inteligência académica se demonstra suficiente para garantir o sucesso profissional, situação que levou diversos teóricos a desenvolver modelos do indivíduo alternativos ao puramente racionalista (Pacheco \& Fernández-Berrocal, 2004). 
Desse modo, também a inteligência emocional deve ser aprendida, através de uma prática continuada. Os alunos necessitam de modelos, exemplos e atividades pedagógicas para aprenderem a lidar com as suas emoções e saberem como potenciá-las na sua atividade profissional. O ensino emocional é, por isso, mais um desafio para os educadores e para a escola.

De acordo com o pensamento de Perrenoud (1999) e Boterf (2001), as soft skills são tão importantes como as competências críticas (hard skills) na formação integral do aluno: enquanto as hard skills são vistas como a "faculdade de mobilizar um conjunto de recursos cognitivos (saberes, capacidades, informações, etc.) para solucionar com pertinência e eficácia uma série de situações" (Perrenoud, 1999, p. 13), as soft skills contribuem para a capacidade do indivíduo gerir e organizar momentos de aprendizagem, conceber mecanismos de diferenciação, trabalhar em equipa, participar na tomada de decisões (seja na sua IES, enquanto estudantes, seja na organização, enquanto colaboradores), bem como enfrentar os deveres éticos e dilemas da sua profissão. Ou, de acordo com as palavras de Bilhim (2009, p. 250) as hard skills "são fundamentais para que o indivíduo seja tido como competente no seu trabalho" e as soft skills "permitem diferenciar as realizações inter-indivíduos".

Mas trabalhar soft skills pode ser deveras desafiante "porque são subjectivos e criam dificuldades na avaliação consistente dos resultados dos alunos" (Englan et al., 2020, p. 108), o que exige que os docentes preparem modelos semiestruturados, nos quais clarifiquem quais são as suas expetativas em relação à atuação dos alunos e de que forma eles terão o seu desempenho avaliado, de forma contínua. Ou seja, os critérios processuais e de avaliação devem ser pensados e organizados de forma a que consigam verificar a evolução dos alunos ao longo do processo, conseguindo sistematizar e validar a aquisição das competências (hard e soft), através do cumprimento de tarefas pré-definidas pelo docente, de acordo com um cronograma ou roteiro de trabalho (Lanz, 2016). Assim, concordamos com Kussmaul (2020, p. 36) quando este afirma: "Students should interact with one another to practice skills and construct their own understanding, with assistance from a teacher acting as a coach and guide-not a lecturer".

\subsection{Metodologias ativas e ensino colaborativo}

A mudança do paradigma dos processos de ensino e aprendizagem no ensino superior, passando a desenvolver-se e a centrar-se em estratégias ativas e colaborativas, favorece, no nosso entender, a própria aquisição do conhecimento pelos alunos, na medida em que aprendem melhor quando são diretamente envolvidos nas atividades de ensino e de aprendizagem, promovendo-se ainda a sua capacidade de pensamento criativo e crítico, em relação às situações apresentadas. Ou seja, a par das capacidades cognitivas e científicas, a formação in- 
tegral do aluno exigirá também o uso (e respetivo treino) da sua inteligência emocional. Além disso, o ensino colaborativo, "além de promover a melhoria dos processos de ensino e de aprendizagem dos estudantes, ... também potencializa a promoção do desenvolvimento pessoal e profissional dos próprios educadores" (Konig \& Bridi, 2019, p. 283).

Esse processo de transformação exige, portanto, que o professor assuma um papel de orientação de todo o trabalho do aluno, identificando as suas necessidades e especificidades, definindo os resultados a alcançar e as estratégias mais adequadas a serem utilizadas nesse percurso.

A aprendizagem ativa é, assim, percebida como

a holistic philosophy for a humanistic vision in higher education, where individuals, groups, institutions,... contribute to a global transformation .... Active learning is a transformative process that brings together knowledge artifacts, learning contexts, humans, and social problems as well as challenges for the present and future of our societies (Misseyanni et al., 2018, p. 42-43).

A formação no ensino superior deve, por isso, apostar em diversos métodos que convirjam na aquisição e consolidação das competências, preparando os futuros profissionais a três níveis fundamentais: aliando o saber-saber (conhecimentos científicos), o saber ser/estar (postura e assertividade) e o saber-fazer (realização de tarefas) de forma integrada. Desta forma, o aluno e futuro profissional conseguirá mobilizar e conjugar todas essas capacidades para conseguir resolver novas situações (Boterf, 2001). Este esforço iniciado na escola (entre educadores e educandos) deve envolver as próprias entidades empregadoras, promovendo-se uma cooperação estratégica, onde se evidenciam três vetores indissociáveis: o saber interagir, o poder interagir e o querer interagir (Santos \& Bonito, 2010).

Destarte, "uma sala de aula onde equipas de estudantes colaboram activamente para processar informação; pensam criticamente sobre os problemas; identificam e avaliam possíveis soluções; e partilham ideias e perguntas umas com as outras" (Kussmaul, 2020, p. 35), será uma turma muito mais pró-ativa e envolvida no processo de aprendizagem.

A capacidade de demonstrar ao aluno o seu papel pró-ativo no processo de construção da sua aprendizagem é fulcral para o sucesso da aprendizagem colaborativa - o aluno consciencializa-se da sua responsabilidade no seu percurso formativo. O professor terá o papel de planificar e direcionar a aprendizagem, controlando as suas capacidades metacognitivas e assegurando que as competências e os conhecimentos são devidamente adquiridos.

Ao longo do tempo têm sido apresentadas diversas estratégias para promover o ensino colaborativo: a aprendizagem baseada em estudo de casos, progra- 
mação feita por pares, formação realizada por pares, aprendizagem em equipa liderada por pares, aprendizagem baseada em projetos ou aprendizagem por inquéritos de processos orientados, entre outras. Em todas as propostas, verificamos o esforço que é feito para percecionar as melhorias nos resultados dos alunos, à medida que passam de um estado passivo (receber informação) para estados ativos e construtivos (gerar compreensão) e, finalmente, para o estado interativo (discussão entre pares) (Kussmaul, 2020).

O ensino da área da gestão de eventos tem assumido uma importância crescente, num mundo globalizado e em permanente evolução e concorrência, onde as organizações, sejam elas públicas ou privadas, veem-se obrigadas a desenvolver atividades que favoreçam a sua imagem organizacional e salvaguardem o seu posicionamento nos meios envolvente e transacional. Como é uma área recente na formação superior, não terá a profundidade científica de outras áreas mais tradicionais, sendo ainda influenciado por múltiplos fatores, tais como a presença cada vez maior da mulher no mercado de trabalho, o impacto do turismo na economia mundial, o crescimento mundial, a aposta em eventos internacional, independentemente das diferenças culturais ou as tendências de marketing, entre muitas outras.

Saber planear, organizar e realizar um evento é uma função central de um secretário/assessor em qualquer organização, dado que em cada atividade se pretende dar uma imagem de profissionalismo, prestígio e excelência. Todavia, "um bom organizador/gestor de eventos deve ser um "fantasma", isto é, deve conseguir planear, realizar o evento e resolver quaisquer imprevistos sem ser notado e sem que os participantes do evento se apercebam de qualquer problema" (Santos, 2019, p. 120).

Perante tantas incertezas, resta-nos uma certeza - aos profissionais que exerçam funções nesta área é-lhes exigido uma capacidade de polivalência e multitasking, garantindo que, pelo mínimo custo possível (e, muitas vezes, com recursos exíguos ou em curtos períodos de tempo), consigam alcançar todos os objetivos previstos pela organização (conseguir prestígio, publicitação da responsabilidade social da organização, divulgação de produtos ou serviços, valorização da organização na comunidade, entre outros). Será a esses desafios que a formação superior nesta área terá de responder, preparando os alunos para uma área competitiva, exigente e, ainda, negligenciada e subvalorizada.

\section{Metodologia}

Este trabalho seguiu uma metodologia humanístico-interpretativa, onde se pretende apresentar de forma essencialmente descritiva e reflexiva, com um suporte teórico prévio acerca dos conceitos chave (ensino ativo e colaborativo, 
competências críticas, soft skills e gestão de eventos), da experiência obtida, entre 2008 a 2019, na lecionação de conteúdos programáticos de gestão de eventos, na licenciatura de Secretariado de Administração, na Escola Superior de Tecnologia e Gestão de Lamego, uma das unidades orgânicas do Instituto Politécnico de Viseu.

É um estudo de caso descritivo único (Yin, 2005), tendo os seguintes objetivos: 1) detalhar exaustivamente as ferramentas, processo e mecanismos de acompanhamento e avaliação, bem como demonstrar a importância destes processos de ensino e de aprendizagem para a formação integral dos alunos; 2) apresentar a estratégia de ensino e avaliação em uso (todas as ferramentas de ensino e avaliação) e como elas ajudam os alunos na aquisição de conhecimentos e competências para o desempenho de funções na área da gestão de eventos; e 3) demonstrar como tais estratégias estimulam, facilitam e avaliam o desempenho dos alunos em diferentes níveis de aquisição de conhecimento, seguidas de metodologias que obrigam ao envolvimento do aluno ao longo do processo de aprendizagem (atividades em grupo, que estimulem a interação e a cooperação na busca de um objetivo comum) dos conteúdos programáticos de gestão de eventos.

Como já referimos, este estudo descritivo aborda uma unidade curricular da licenciatura de Secretariado de Administração, da Escola Superior de Tecnologia e Gestão de Lamego, do Instituto Politécnico de Viseu, ao longo de 12 anos de lecionação, abrangendo todos os alunos inscritos e trabalhos desenvolvidos na mesma. Pretende-se, por isso, apresentar exaustivamente a metodologia de avaliação e de ensino utilizada na unidade curricular em estudo, realçando a forma como se pretende que essa metodologia vá ao encontro da aquisição das competências e dos conteúdos programáticos.

\section{Apresentação e discussão reflexiva - metodologias de ensino e de aprendizagem adotadas}

Os conteúdos programáticos de gestão de eventos fazem parte do 4으 semestre da licenciatura de Secretariado de Administração (com um total de 6 semestres) e, desde o início da sua lecionação, procurou-se incutir nos alunos competências técnicas, organizativas e comunicacionais adequadas ao desempenho dessas funções no mercado de trabalho.

Em termos gerais, os conteúdos programáticos da unidade curricular estão definidos da seguinte forma: 
Tabela 1. Conteúdos programáticos da unidade curricular. Fonte: Elaboração própria.

GESTÃO DE EVENTOS: Classificação de Eventos; Tipologias de Eventos; Fases do Evento: Conceção, Pré-Evento, Per evento e Pós evento.

PROTOCOLO: Breves noções de protocolo; Listas de convidados; Convites formais; Cartões-de-visita; Regras práticas e protocolares; Receção de convidados num edifício; Colocação de bandeiras nas várias situações possíveis; Precedências no protocolo (ordenação de pessoas).

COMUNICAÇÃO: Estratégia de comunicação e marketing de eventos.

Os conteúdos programáticos apresentados correspondem a um total de 45 horas letivas e a 5 ECTS (com um total de 135 horas de trabalho), correspondendo a sensivelmente $50 \%$ de uma unidade curricular mais abrangente com um total de 10 ECTS, denominada Práticas e Técnicas de Secretariado II.

Associados a estes conteúdos programáticos, foram definidos os seguintes objetivos:

Tabela 2. Objetivos gerais da unidade curricular. Fonte: Elaboração própria.

Dotar os discentes, através de simulações de situações reais e de conhecimentos teóricos, de capacidades pessoais e profissionais, teóricas e práticas, que permitam uma maior facilidade de adaptação aos diferentes métodos organizacionais e aos novos instrumentos de trabalho.

Preparar o(a) secretário(a) para o desenvolvimento profissional em diferentes ambientes profissionais.

Sensibilizar e dar a conhecer aos discentes novos instrumentos e ferramentas de apoio ao desempenho profissional.

Transmitir os conhecimentos teóricos e técnicos sobre a gestão de eventos.

Conduzir à assimilação prévia de conceitos teóricos básicos, para a elaboração e resolução posterior de simulações/casos práticos, preparando os discentes paras as exigências com que cada um se depara no seu quotidiano profissional, atual e/ou futuro. Desenvolver a capacidade de fluência escrita e oral.

De acordo com a literatura, a eficiente gestão de eventos implica sabermos qual pertinência de cada evento, respondendo a cinco questões: o quê?, quando?, porquê?, onde? e quem?. Ou seja, antes de nos decidirmos pela realização de um evento, teremos de saber:

“- que tipo de evento é mais adequado para a nossa organização, tendo em conta os custos inerentes e os objetivos que pretendemos alcançar;

- qual a melhor altura do ano (data e hora) para realizarmos o evento, para conseguirmos maximizar o seu impacto; 
- quais os objetivos que pretendemos alcançar com a realização do evento e quais os resultados/retorno expectáveis;

- qual o melhor espaço físico para a sua realização e quais as necessidades logísticas/físicas complementares que serão necessárias;

- e, finalmente, a quem se destina o evento e deverá estar presente. Embora este seja o último item que referimos, todos os pontos anteriores convergem na identificação clara do público-alvo que queremos atingir com o nosso evento, devendo ser definidos tendo em conta o seu perfil, os seus interesses e os seus gostos" (Santos, 2019, p. 120).

A capacidade de atuar neste campo profissional exige, então, o domínio de hard skills e soft skills para que o profissional consiga ter o sucesso esperado. Essas competências são também as identificadas no programa curricular, de acordo com a proposta infra:

Tabela 3. Proposta de competências associadas aos conteúdos programáticos e objetivos. Fonte: Elaboração própria.

Competências críticas (hard skills)

Conhecimento das fases do evento

Domínio das regras protocolares

Capacidade de gestão documental e elaboração de modelos de comunicação (escritos/verbais e gráficos)

Domínio das ferramentas de apoio à gestão de eventos (cronograma, checklist, mailing list, convite, poster, merchandising, desdobrável, etc.) Conhecimento acerca de $\mathrm{TIC}$ de apoio à gestão de eventos

Conhecimento da estratégia de comunicação e marketing de um evento

Conhecimento de gestão e exequibilidade financeira do evento

Capacidade de execução e avaliação de um evento

\section{Soft skills}

Trabalho em equipa

Gestão de prazos e timings para cumprir tarefas

Capacidade de liderança e gestão de equipas

Capacidade de comunicação com diversos targets

Capacidade de resolução de problemas/ imprevistos

Capacidade de negociação

Entreajuda entre pares

Gestão de stress

Tratando-se de uma unidade curricular composta por aulas teóricas e práticas, pretende-se que todas as sessões sejam interativas, incentivando-se a intervenção oral sobre os temas abordados, fazendo-se ainda apelo aos meios audiovisuais. Sempre que possível, são promovidos também seminários extracurriculares que complementem os conhecimentos teóricos tratados nas sessões de contacto presencial. 
Na apresentação dos conteúdos programáticos, estão implícitos processos lógicos e metódicos que concorrem para atingir os vários objetivos previstos, ao exigir o conhecimento, a compreensão, a análise crítica, a tomada de decisão, a aplicação prática de técnicas e métodos para solucionar problemas e gerar informação e soluções por parte dos alunos.

Através da adoção de um trabalho prático como principal mecanismo de avaliação, pretende-se motivar os alunos para a investigação empírica nesta área, corresponsabilizando-os pelo seu percurso formativo e pelo êxito dos trabalhos selecionados e executados.

Assim, as metodologias de ensino e de avaliação adotadas procuram refletir a preocupação em articular conhecimento e compreensão (aulas teóricas) com a aplicação prática diante de exercícios que requerem análise crítica, sistematização e aplicação de técnicas e conhecimentos adequados a cada situação (aulas práticas e trabalho de campo). Os trabalhos realizados nas aulas e fora das sessões de contacto, em grupos de alunos, contribuem para o desenvolvimento das competências relacionadas com o trabalho em equipa, a responsabilidade, a tolerância, a gestão do trabalho e suas obrigações e a gestão do stress, entre outras.

Por seu lado, a conceção e realização de um evento, no qual os alunos (também em grupo) tomam todas as decisões relacionadas com as várias fases do processo de gestão de eventos, espelhando, dessa forma, todos os conhecimentos que vão gradualmente adquirindo nas aulas teóricas, enquadra os objetivos e as competências estabelecidas para este módulo da unidade curricular.

A avaliação deste módulo baseia-se na organização e realização de um evento real (desde a sua conceção à sua avaliação) e respetiva entrega final do relatório e portefólio. Pretende-se, desta forma, criar espaços de aplicação real e/ou simulada dos conhecimentos lecionados, consolidando a aquisição desse conhecimento e da capacidade oral e escrita dos alunos ao nível das competências do secretariado e assessoria, no âmbito da gestão de eventos.

Além de tudo o que foi exposto, gostaríamos de realçar os seguintes dados, relativos ao funcionamento da unidade curricular, baseada em diferentes técnicas de ensino colaborativo:

- Após a apresentação dos conteúdos programáticos, objetivos de aprendizagem, competências a adquirir e metodologia de ensino, é negociado anualmente com cada turma a organização de grupos, temas e tipologia do evento a realizar por cada grupo;

- Após a definição dos eventos, é negociada e apresentada uma calendarização das metas e etapas a concretizar (entrega de cada parte do trabalho e reali- 
zação de tarefas, para acompanhamento e monitorização da evolução de cada grupo). Esta etapa é negociada entre docente e os grupos de trabalho criados;

- 50\% das aulas são reservadas à a plicação prática dos conteúdos veiculados nas sessões teóricas: essas sessões servem essencialmente para planificação das tarefas a realizar, entre os membros de cada grupo, bem como para orientação pelo docente, onde este observa (podendo intervir para esclarecer, apoiar ou retificar) as dinâmicas comunicacionais e de interação entre os membros de cada grupo, a capacidade de trabalho em equipa e de resolução de conflitos/ imprevistos, gestão do trabalho e distribuição de tarefas, bem como a utilização de ferramentas para desenvolver o trabalho definido e alcançar os resultados definidos;

- Além das sessões presenciais, cada grupo deve enviar o relatório atualizado e restante material desenvolvido, com uma periodicidade quinzenal, para a docente poder analisar e apresentar as propostas de correção necessárias, num prazo de 48 horas (para não colocar em causa o decurso das tarefas preconizadas);

- Cada grupo tem total liberdade criativa para a elaboração da imagem e material gráfico do evento definido, devendo elaborar toda a documentação de uma forma uniforme e respeitando as regras protocolares estudadas. Nesta etapa, os alunos são convidados a utilizarem ferramentas multimédia e a desenvolverem modelos de comunicação verbal (conteúdos estudados noutras unidades curriculares), promovendo-se a interdisciplinaridade do conhecimento;

- Após correção e aprovação de todos os modelos de comunicação / divulgação do evento, cada grupo é encorajado a envidar todos os esforços para garantir a exequibilidade do seu evento, quer ao nível financeiro, quer ao nível de recursos necessários (como nenhum aluno poderá assumir qualquer custo com as tarefas relacionadas com o evento, os grupos vêem-se obrigados a angariar apoios e patrocínios que assegurem a totalidade das despesas previstas, o que exige o treino da comunicação assertiva e da capacidade de negociação por parte dos alunos, bem como a adaptação do discurso a diferentes interlocutores);

- No final de cada semestre, os alunos são convidados a realizar uma sessão de avaliação acerca do decurso da unidade curricular. Apesar da elevada carga de trabalho associada normalmente referida pelos alunos (especialmente pelos trabalhadores-estudantes), temos verificado uma concordância total com a metodologia implementada. Além dessa sessão presencial, os alunos são também convidados a avaliar os processos de ensino e de aprendizagem, através do preenchimento de um inquérito de satisfação em relação a cada unidade curricular. Os resultados que apresentamos (bem como as melhorias intro- 
duzidas na avaliação) plasmam o grau de satisfação e as propostas apresentadas nesses inquéritos (com uma taxa de adesão de resposta de cerca 85\%, em média, ao longo dos anos em estudo).

De facto, os alunos têm defendido que a responsabilidade que sentem ao longo do semestre para alcançar os objetivos definidos e negociados com a docente, bem como a aplicação de todos os conhecimentos, torna-se desafiante e permite-Ihes uma melhor assimilação dos conteúdos teóricos e técnicos, e uma preparação mais adequada para o mercado de trabalho, sentindo-se mais seguros em relação às suas capacidades de trabalho e de comunicação. Ao longo dos anos, a única situação que foi apresentada pelos discentes como proposta de melhoria foi a referente ao momento de realização dos eventos (em vez de serem concentrados nas semanas finais do semestre, os alunos aconselharam que os eventos fossem previstos/negociados para o mês de maio, o que evitava que os mesmos coincidissem com as avaliações das restantes unidades curriculares e permitia uma melhor gestão do tempo pelos alunos, para planificar o seu estudo). Esta proposta apresentada no ano letivo de 2014-2015, passou a ser implementada a partir de então até à atualidade, já que a docente concordou que esta sugestão seria benéfica para o processo de aprendizagem.

\section{Considerações finais}

A promoção do ensino ativo e colaborativo nas IES constitui um enorme desafio, mas também uma arma em relação à desmotivação ou à ideia de afastamento entre as práticas desenvolvidas e conhecimentos transmitidos no ensino superior e as entidades empregadoras (e as suas reais necessidades, em relação às competências que esperam dos seus colaboradores): qualquer processo de ensino e de aprendizagem que permita que o aluno se sinta pró-ativo e corresponsável pela aquisição de conhecimento e competências será sempre uma ensino mais eficiente ao nível dos resultados alcançados.

Como verificámos, o ensino colaborativo, baseado na programação negociada com os estudantes e na aprendizagem em equipa liderada por pares, são mecanismos que podem potenciar o interesse e a motivação dos alunos, facilitando o sucesso das unidades curriculares ao nível da transferência de conhecimento.

Criadas com o objetivo de serem concebidas como instrumentos de mudança e transformação social orientados para o enriquecimento da vida humana, as instituições de ensino, em geral, têm a missão da realização máxima do potencial inerente ao indivíduo, visando a sua formação integral e as instituições de ensino superior, em particular, acarretam, indubitavelmente benefícios não só para quem as frequenta, como também para a sociedade, com claras vantagens que se refletem em múltiplos aspetos. 
A opção por estratégias de aprendizagem que incluam o desenvolvimento de competências como a criatividade, o trabalho em equipa, a comunicação e a solidariedade, pretendem que, no final, se consiga formar um aluno que seja capaz de enfrentar a mudança e consiga, na escola, que lhe seja incutida a capacidade e o desejo de busca permanente.

A passagem de um modelo que privilegia a lógica da instrução e transmissão de informação para um modelo pedagógico baseado na prática colaborativa de procura de conhecimento, é um desafio constante com que lidam todos os dias os professores e este facto exige, também, um perfil de professor mais ágil, mais atento e, claro está, mais democrático, já que a hierarquização de poderes também se transfigura.

É inquestionável, então, que a escola encontre métodos de formação e de avaliação eficazes que contemplem o desenvolvimento das soft skills no contexto de ensino e de aprendizagem, que conduzam à formação de um aluno que é capaz de assumir riscos, de o ensinar que o "aprender a aprender" é uma necessidade, que o ajudem a adaptar-se à mudança. Os métodos de formação e avaliação devem valorizar o desenvolvimento de competências pessoais e sociais que respondem à necessidade de comportamentos mais autónomos, de aprender rapidamente e de responder a novas situações e desafios colocados pela sociedade.

O segredo não pode estar, como outrora, na mera memorização de conteúdos ou na utilização de instrumentos de avaliação que valorizem apenas a capacidade de reter informação (memorização essa que, muitas vezes, se tornava efémera e sem impacto no verdadeiro conhecimento dos alunos), passando a centrarse na forma como essa informação é tratada, ou seja, o "aprender a aprender" e sobretudo estar preparado para aprender ao longo de toda a vida, atualizando conhecimento e adaptando as competências às necessidades laborais.

Vivemos num mundo onde a complexidade dos fenómenos gera a necessidade de colocar o aluno na posição de criador de conhecimentos, sendo para isso necessário dotá-lo da capacidade de saber pensar, ter sentido crítico e ser criativo, mais do que apreender conceitos avulsos que não são utilizáveis do ponto de vista da resolução de problemas concretos que se lhe coloquem. Para isso, e sem deixar de ter um papel crucial no processo, exige-se que o professor seja reflexivo e procure estratégias de acompanhamento e de avaliação que se coadunam com o contexto em que ensina, sob pena de não conseguir desenvolver as competências necessárias que a sociedade exigirá do aluno quando a escola terminar a sua missão de o formar. Numa área de lecionação recente, como é a área da gestão de eventos, a qual ainda não se encontra consolidada enquanto corpus teórico apesar da sua extrema importância no mundo do trabalho nas mais diversas atividades, a capacidade de envolver os alunos facilitará a aquisição, por 
parte deles, das competências críticas e das soft skills adequadas à sua futura atuação e desempenho profissional.

Com a visão de "fazer evoluir a Instituição para um modelo de referência, nos planos da educação, formação, investigação, e intervenção na comunidade, numa lógica de valorização de recursos humanos, integrando uma perspetiva de formação ao longo da vida ajustada aos novos desafios" (ESTGL, s.d.), a nossa Escola tem contribuído, desde a altura em que foi criada, para a valorização do território onde está inserida e é, como todas as instituições de ensino, um instrumento não apenas de mudança, mas também de transformação social que pretende o enriquecimento de todos quantos a frequentam. De facto, qualquer Escola só fará sentido se responder às necessidades formativas do território onde se insere e se qualificar ativos que respondam a essas mesmas necessidades.

Nós professores, também enquanto agentes educativos, temos o dever de concretizar a missão das instituições que representamos, não esquecer a missão da nossa profissão e, acima de tudo, nunca negligenciar a figura central deste processo todo, ou seja, nunca descurar a importância e o papel primordial do aluno. Nesse sentido, e com o objetivo de sistematizar as perceções dos estudantes acerca das metodologias utilizadas e refinadas ao longo dos últimos anos, pretendemos aprofundar o nosso presente estudo, como forma de sermos capazes de apresentar uma análise descritiva e inferencial que consolide o conhecimento e a prática docente, na área da gestão de eventos.

\section{Referências bibliográficas}

Bilhim, J. A. (2009). Gestão Estratégica de Recursos Humanos. Instituto Superior de Ciências Sociais e Políticas.

Boterf, G. L. (2001). Ingeniería de las competencias. Ediciones Gestion 2000.

England, T. K., Nagel, G. L., \& Salter, S. (2020). Using collaborative learning to develop students' soft skills. Journal of Education for Business, 95(2) 106-114. https:/ / doi.org/10.1080/08832323.2019.1599797

ESTGL. (s.d.). Missão. Obtido de ESTGL: https://www.estgl.ipv.pt/docs/missao.pdf

Fernández-Berrocal, P., Salovey, P., Ramos, N., \& Extremera, N. (2001). Cultura, inteligencia emocional percibida y ajuste emocional: un estudio preliminar. Revista Electrónica de
Motivación y Emoción, 7(4). http:// reme.uji.es/ llista/llista.htm

International Commission on Education for the Twenty-first century. (1996). Learning: the treasure within. UNESCO. https://unesdoc. unesco.org/ark:/48223/pf0000109590.

Konig, F. R., \& Bridi, F. R. S. (2019). O ensino colaborativo e a gestão das práticas pedagógicas: avaliando efeitos. Revista Eletrônica de Educação, 13(1), 278-290. http:/ / dx.doi.org/10.14244/198271992695.

Kussmaul, C. (2020). Guiding students to develop essential skills. Communications of the ACM, 63(2), 35-37. https://doi. org $/ 10.1145 / 3376893$

Lanz, H. R. (2016). Reflexões sobre práticas de sala de aula e competências na formação 
de professores da universidade de Colónia, Alemanha. Revista Practicum, 1, 1, 99-113. https://doi.org/10.24310/RevPracticumrep. v1i1.8259

Misseyanni, A., Lytras, M., Papadopoulou, P., \& Maroul, C. (Eds.) (2018). Active learning strategies in higher education: Teaching for leadership, Innovation, and creativity. Emerald Publishing Limited.

Pacheco, N. E., \& Fernández-Berrocal, P. (2004). EL papel de la inteleigência emocional em el alumnado: evidencias empíricas. Revista Electrónica de Envestigación Educativa, 2(6), 1-17. https://bit.ly/3DbIRu8
Perrenoud, P. (1999). Construire des compétences, tout um programme. Vie pédagogique, 112, 16-20. https://bit.ly/3Db83kI

Santos, P., \& Bonito, A. (fev. 2010) Interagir com o mundo do trabalho - o ensino colaborativo e o voluntariado. Atas do Congresso Ibérico Ensino Superior em Mudança: Tensões e Possibilidades, Universidade do Minho https://bit.ly/317jaVu

Santos, P.M. (2019). Secretariado e planeamento estratégico. Assessoria e gestão de eventos. Ediç̧ões Esgotadas.

Yin, R. (2005). Estudo de Caso. Planejamento e Métodos. Bookman.

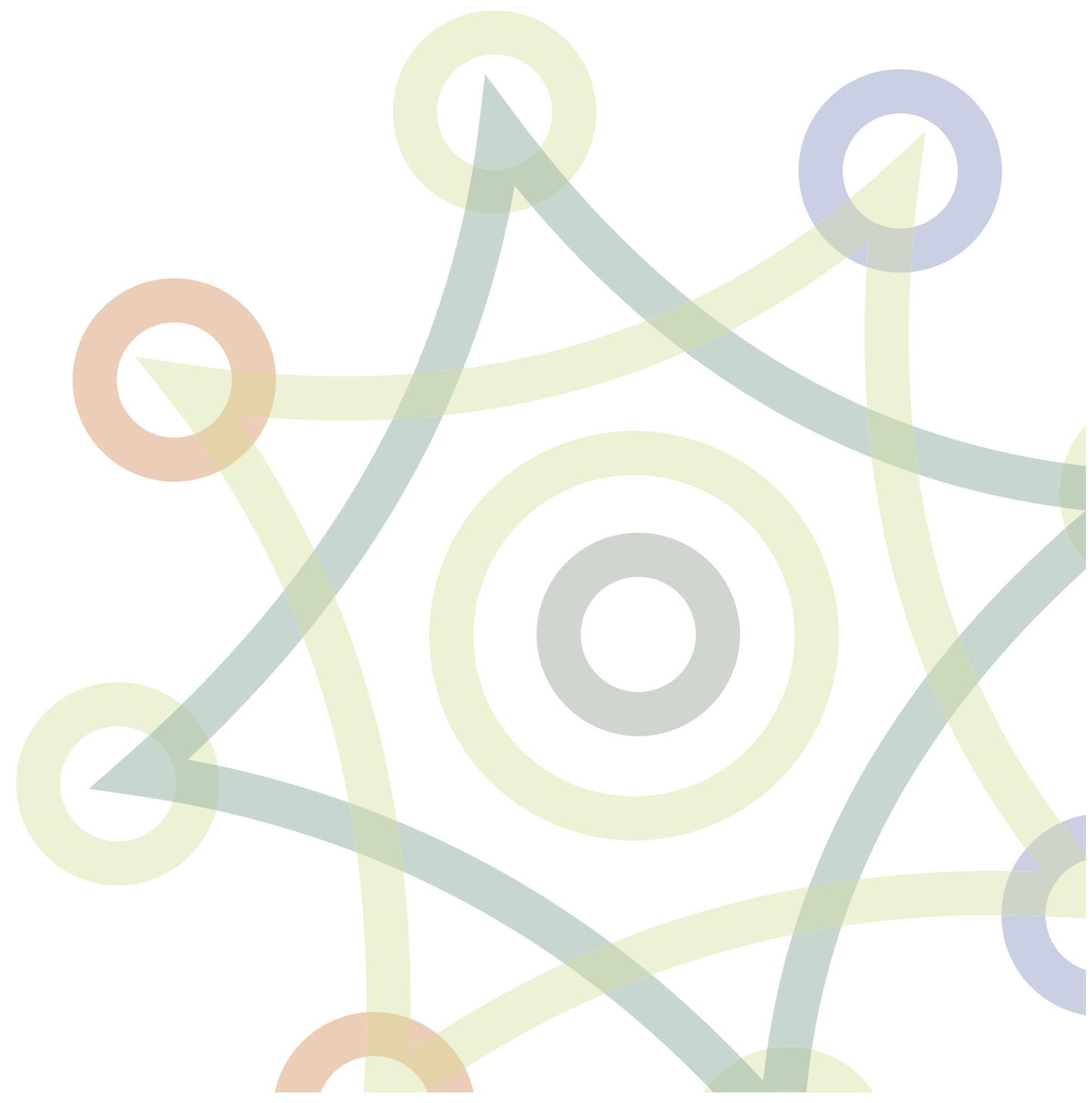

